\title{
Re-excision Rates and Local Recurrence in Breast Cancer Patients Undergoing Breast Conserving Therapy
}

\author{
Reexzisions- und Lokalrezidivrate bei Brustkrebspatientinnen \\ nach brusterhaltender Operation
}

Authors

Affiliations
M. Dieterich ${ }^{1}$, H. Dieterich ${ }^{2}$, H. Moch ${ }^{3}$, C. Rosso ${ }^{2,3}$

1 Universitätsfrauenklinik und Poliklinik, University of Rostock, Rostock

${ }^{2}$ Breast Center Rheinfelden, Rheinfelden

${ }^{3}$ Institute of Clinical Pathology, University of Zurich, Zurich, Switzerland

\author{
Key words \\ - oncoplastic surgery \\ - local recurrence \\ - breast-conserving therapy \\ - margin status \\ - re-excision \\ - breast cancer \\ Schlüsselwörter \\ - onkoplastische Operation \\ - Lokalrezidiv \\ - brusterhaltende Operation \\ - Tumorrand \\ - Reexzision \\ - Brustkrebs
}

\section{Abstract \\ V}

Background: Controversy continues over the impact of re-excision (RE) on local recurrence (LR) in patients with invasive breast cancer.

Patients and Methods: We investigated factors which could effect RE rates in patients undergoing breast-conserving or oncoplastic surgery. Between 2000 and 2003, 489 patients with stage pT1-pT2 or pN0/1 tumors were evaluated. 74 patients fulfilled the inclusion criteria. Patients were categorized into 3 groups: no RE ( $n=25)$, RE during primary surgery $(n=28)$, and RE performed during secondary or even tertiary procedure $(n=21)$. All tumor slides were re-evaluated by a pathologist specializing in breast cancer.

Results: Mean follow-up was 70 months with an overall LR rate of $4.1 \%$. Binary logistic regression revealed no tumor-specific risk factors for RE. There was no LR in the group of patients who did not have RE. There was one case of LR in the group of patients who had RE during primary surgery. Two cases of LR were observed in the group of patients who had two or more surgical procedures. Conclusion: New risk factors for increased RE rates were not observed, reflecting the inconsistent data on risk factors for RE. However, breast cancers should be excised in a single procedure and oncoplastic procedures should be considered.

revised 28.10.2012

accepted 28.10.2012

Bibliography

DOI http://dx.doi.org/

10.1055/s-0032-1327980

Geburtsh Frauenheilk 2012; 72:

1018-1023 @ Georg Thieme

Verlag KG Stuttgart · New York . ISSN 0016-5751

\section{Correspondence}

\section{Dr. Max Dieterich}

University of Rostock

Universitätsfrauenklinik

und Poliklinik

Südring 81

18059 Rostock

max.dieterich@uni-rostock.de

\section{Introduction $\nabla$}

The primary goal for all breast cancer (BC) patients undergoing breast-conserving (BCT) or oncoplastic surgery (OPS) is to achieve tumor-free margins in a single surgical procedure. However, it is not uncommon for $\mathrm{BC}$ patients to undergo more than one surgical procedure before they

\section{Zusammenfassung}

$\nabla$

Hintergrund: Der Einfluss von Reexzisionen (RE) auf die Lokalrezidivate (LR) bei Brustkrebspatientinnen wird nach wie vor kontrovers diskutiert.

Patienten und Methoden: Diese Studie untersucht Einflussfaktoren auf die RE-Rate bei Brustkrebspatientinnen nach brusterhaltender oder onkoplastischer Operation. Zwischen 2000 und 2003 wurden 489 Patientinnen mit pT1-pT2und pNo/1-Tumoren ausgewertet. 74 Patientinnen erfüllten die Einschlusskriterien und wurden in 3 Gruppen unterteilt: keine RE $(n=25)$, RE während der Primäroperation und RE in einer sekundären Operation $(n=21)$. Alle Tumorblöcke wurden durch einen auf Brustkrebs spezialisierten Pathologen reevaluiert.

Ergebnisse: Der durchschnittliche Beobachtungszeitraum, mit einer LR-Rate von $4,1 \%$, betrug 70 Monate. Binäre logistische Regressionsanalyse ergab keine tumorspezifischen Risikofaktoren für eine RE. Kein Rezidiv trat in der Gruppe ohne RE auf. In der Gruppe mit RE während der Primäroperation trat ein LR, und in der Gruppe mit RE in einer sekundären oder weiteren Operation traten 2 LR auf.

Zusammenfassung: Neue Risikofaktoren für eine erhöhte RE-Rate konnten nicht gefunden werden und spiegeln die inkonsistente Datenlage wider. Brustkrebs sollte des ungeachtet in einer Operation entfernt werden, wobei onkoplastische Techniken berücksichtigt werden müssen. achieve tumor-free margins [1-3]. In patients with invasive ductal carcinoma (IDC), an accompanying ductal carcinoma in situ (DCIS) is diagnosed in approximately $30-60 \%$ of cases, making the primary attempt to achieve tumor-free margins challenging $[4,5]$. Positive or close margins after BCT are described in up to $40 \%$ of patients with re-excision (RE) rates of up to $57 \%$ in pa- 
tients with accompanying DCIS [6-8]. National and international guidelines recommend mastectomy if no adequate margins are achieved after repeated $\mathrm{RE}[9,10]$. However, no limits have been placed on the number of RE procedures undertaken until mastectomy is advisable. Whether the need for multiple RE procedures is associated with an increased risk of local recurrence (LR) is still controversially discussed $[3,11-13,35]$. If OPS is done, it is possible to remove larger volumes of up to $20-40 \%$ of the initial breast tissue without compromising the oncologic or esthetic result [14]. The goal of BCT and OPS is to achieve adequate margins with optimal loco-regional tumor control and optimal cosmetic results but without compromising oncologic safety.

The purpose of this study was twofold: firstly, to determine the factors associated with an increased risk for RE and secondly, to investigate whether the rate of LR is correlated to the number of $\mathrm{RE}$ in $\mathrm{BC}$ patients undergoing BCT or OPS.

\section{Patients and Methods}

$\nabla$

The data of all patients with pT1-pT2 tumors undergoing BCT or OPS in a single institution (Breast Cancer Center Rheinfelden, Germany) between January 2000 and December 2003 were retrospectively reviewed.

Inclusion criteria for the study were: preoperative, histologically confirmed BC (by high-speed biopsy), tumor stage cT1-2, nodal status cN0-1, no distant metastasis, primary planned procedure either BCT or OPS (local and glandular flaps, local advancement flaps), invasive carcinoma, complete data of follow-up and patients to receive postoperative radiation. Exclusion criteria were: tumor stage $>$ cT2, lymph node status > pN1, distant metastases, bilateral carcinoma, not eligible for BCT or OPS, patients without complete data of follow-up, incomplete or unavailable histological data/slides, histological evaluation performed by someone other than the reference pathologist, and patients with only DCIS or LCIS (lobular carcinoma in situ).

Patients were divided into 3 groups: group 1: no RE necessary; group 2: RE done during primary surgery; and group 3: RE in two or more surgeries. All tumors were localized preoperatively using needle localization.

Frozen section margin examination was done intraoperatively to examine whether margins were tumor-free. If tumor margins were positive, RE was performed during the same surgical procedure. No additional frozen section of the RE specimen was done. If margins were still positive in the final histological report, patients were scheduled for RE. All patients in group 3 were informed preoperatively of their potentially increased risk of LR, and mastectomy was recommended. If the patients requested it, a third RE attempt was performed.

All histo-pathological slides were re-evaluated by one of the coauthors (HM), a pathologist specializing in BC histology. The primary TNM stage was re-evaluated based on the recommendations of the UICC, 6th edition of the TNM system [15]. A positive margin was defined as a margin of less than $1 \mathrm{~mm}$ for the invasive cancer and of less than $3 \mathrm{~mm}$ for the DCIS. These margins were recommended by the pathological reference institute, as there was no international consensus on margins for DCIS at the time of surgery. The following data were taken from the histological reports: resected volume, diameter of the invasive cancer and/or DCIS, margin status of the invasive and/or in situ component, presence or absence of an in situ component (intratumoral and/or peritumoral).
All patients with positive hormone receptors received endocrine therapy (tamoxifen) and adjuvant radiation therapy. Chemotherapy was administered to all patients with positive lymph nodes and to high-risk patients with negative lymph nodes, in accordance with national guidelines [9].

Statistical analysis was done using SPSS (version 15, SPSS Inc., Chicago, IL, USA). Descriptive statistics were computed for continuous and categorical variables. F-test was used to compare means of groups and $\mathrm{X}^{2}$ test to compare numbers in groups. Data are presented as mean value \pm standard deviation; a p-value $<0.05$ was considered to be statistically significant. Binary logistic regression analysis was used to reveal unadjusted significant associations between prognostic variables and the likelihood of RE. For statistical analysis, groups 1 and 2 were merged into a "single surgery" group to identify possible risk factors predictive for additional surgery.

\section{Results}

\section{Patient characteristics and treatment}

127 patients fulfilled the inclusion criteria and were contacted by post to ask about the further course of disease ( Fig. 1). 94 patients (74\%) responded. 20 of the 94 patients were excluded, because they did not qualify for BCT and underwent salvage mastectomy within 1-4 months after initial surgery. The remaining 74 medical records were analyzed with respect to the number of $\mathrm{RE}$ procedures and surgical procedures needed to achieve tumor-free margins. Other data collected included age, type of surgery, tumor stage, nodal status, grading, hormone receptor status, extensive intraductal component (EIC), mean resection volume, tumor size and LR ( Tables 1 and 2). Median follow-up

Table 1 Patient characteristics.

\begin{tabular}{|c|c|c|c|}
\hline Patient characteristics & $B C T(n=40)$ & OPS $(n=34)$ & p-value \\
\hline Age $^{\#}$ & $55.6 \pm 9.0$ & $50.3 \pm 10.1$ & $0.019^{*}$ \\
\hline Tumor (n)* & & & $0.13^{*}$ \\
\hline T1 & 34 & 24 & \\
\hline $\mathrm{T} 2$ & 6 & 10 & \\
\hline Nodal status (n)* & & & $0.13^{*}$ \\
\hline No & 30 & 20 & \\
\hline N1 & 10 & 14 & \\
\hline Grading of invasive CA & & & $0.013^{*}$ \\
\hline G1 & 9 & 2 & \\
\hline G2 & 19 & 11 & \\
\hline G3 & 12 & 21 & \\
\hline Hormone receptor status & & & $0.33^{*}$ \\
\hline Positive & 29 & 21 & \\
\hline negative & 11 & 13 & \\
\hline $\operatorname{EIC}(n)$ & & & $0.16^{*}$ \\
\hline Invasive CA alone & 22 & 23 & \\
\hline$<25 \%$ & 6 & 7 & \\
\hline$>25 \%$ & 12 & 4 & \\
\hline $\begin{array}{l}\text { Mean resection volume } \\
(\mathrm{g})^{\#}\end{array}$ & $95.6 \pm 152.8$ & $321.1 \pm 401.9$ & $0.002^{*}$ \\
\hline Re-excision (n) & & & $0.58^{*}$ \\
\hline Group 1 & 15 & 10 & \\
\hline Group 2 & 13 & 15 & \\
\hline Group 3 & 12 & 9 & \\
\hline Local recurrence & $2(5 \%)$ & $1(2.9 \%)$ & $0.65^{*}$ \\
\hline
\end{tabular}

BCT: breast-conserving therapy; OPS: oncoplastic surgery; \# Data are given as mean \pm SD; SD: standard deviation; EIC: extensive intraductile component; * Pearson's $\mathrm{X}^{2}$ test, F-test, recommendations of the UICC, 6th edition of the TNM system 
362 patients did not fulfill inclusion criteria:

- 43 patients: data of follow-up missing or clinical data incomplete

- 103 patients: histological slides for re-evaluation either incomplete or not available

- 114 patients had primary mastectomy

- 5 patients denied adjuvant radiotherapy

- 2 patients had distant metastasis at diagnosis

- 14 patients had bilateral breast cancer

- 13 patients denied BCT and received mastectomy

- 68 patients had DCIS or LCIS alone

- 33 patients did not respond

- 20 patients underwent mastectomy within 1-4 months

$\mathrm{BCT}$ : breast-conserving therapy

DCIS: ductal carcinoma in situ

LCIS: lobular carcinoma in situ

489 patients with $\mathrm{pT} 1-\mathrm{pT} 2$ or $\mathrm{pNO} / 1$ tumors
Fig. 1 Flow chart of patient selection.

\section{7 patients}

74 patients

for evaluation

Table 2 Characteristics of patients undergoing re-excision (RE).

\begin{tabular}{|c|c|c|c|c|}
\hline & $\begin{array}{l}\text { Group } 1 \\
\text { (no RE) } \\
\text { (n= 25) }\end{array}$ & $\begin{array}{l}\text { Group } 2 \\
\text { (RE during primary surgery) } \\
(n=28)\end{array}$ & $\begin{array}{l}\text { Group } 3 \\
\text { ( } R E \text { in two or more surgeries) } \\
(n=21)\end{array}$ & p-value** \\
\hline Age (years)" & $55.0 \pm 10.7$ & $53.6 \pm 9.2$ & $50.4 \pm 9.4$ & 0.27 \\
\hline Surgery (n) & & & & 0.57 \\
\hline $\mathrm{BCT}$ & 16 & 13 & 14 & \\
\hline OPS & 11 & 15 & 10 & \\
\hline Tumor stage $(\mathbf{n})^{*}$ & & & & 0.47 \\
\hline $\mathrm{T} 1$ & 20 & 20 & 18 & \\
\hline $\mathrm{T} 2$ & 5 & 8 & 3 & \\
\hline Nodal status (n)* & & & & 0.31 \\
\hline NO & 19 & 16 & 15 & \\
\hline N1 & 6 & 12 & 6 & \\
\hline Grading of invasive CA & & & & 0.69 \\
\hline G1 & 3 & 4 & 4 & \\
\hline G2 & 13 & 10 & 7 & \\
\hline G3 & 9 & 14 & 10 & \\
\hline Hormone receptor status & & & & 0.49 \\
\hline Positive & 19 & 17 & 14 & \\
\hline Negative & 6 & 11 & 7 & \\
\hline $\operatorname{EIC}(\mathbf{n})$ & & & & 0.66 \\
\hline Invasive $\mathrm{CA}$ alone & 17 & 17 & 11 & \\
\hline$<25 \%$ & 5 & 4 & 4 & \\
\hline$>25 \%$ & 3 & 7 & 6 & \\
\hline Mean resection volume $(\mathbf{g})^{\#}$ & 141 (range: 19-264) & 231 (range: 96-367) & 224 (range: 96-353) & 0.53 \\
\hline Tumor size (mm) & & & & 0.47 \\
\hline $1-20$ & 20 & 20 & 18 & \\
\hline$>20$ & 5 & 8 & 3 & \\
\hline Local recurrence & 0 & 1 & 2 & 0.26 \\
\hline
\end{tabular}

\# Data are given as mean \pm SD; SD: standard deviation; EIC: extensive intraductile component; ${ }^{*}$ Recommendations of the UICC, 6th edition of the TNM system; ** F-test was used to compare means of groups, $\mathrm{X}^{2}$ test used to compare numbers in groups. 
was 71 months (SD: \pm 12 months, range: 44-91months). 29 patients (39\%) had accompanying DCIS and 45 had IDC (61\%) alone. Pathologic margins were all negative after final excision or RE.

\section{Surgical aspects}

40 patients had BCT and 34 patients underwent OPS. An additional surgical procedure was needed in $30 \%$ of BCT patients and $27.5 \%$ of OPS patients. The mean resection weight in grams was higher in the OPS group compared to the BCT group $(\mathrm{p}<0.002)$. Younger age was associated with increased rates for OPS $(\mathrm{p}=0.019)$.

\section{Re-excision}

Tumor-free margins were achieved during primary surgery in 53 patients (71.6\%). In 25 (33.8\%) of these patients no RE was necessary during surgery while 28 (37.8\%) patients had one RE during primary surgery. Twenty-one (24.8\%) of the 74 patients were scheduled to undergo a secondary surgical procedure, and 3 of these needed a third surgical procedure to achieve tumor-free margins. RE rates in the OPS and BCT groups were comparable $(\mathrm{p}=0.58)$. Tumor-free margins were achieved during primary surgery in $70 \%$ of patients in the BCT group and in $73.5 \%$ of patients in the OPS group. Binary logistic regression of factors predictive for increased risk of RE at initial surgery showed no patient- or tumor-related characteristics as independent predictors for RE (๑ Table 3).

\section{Local recurrence rate}

71 patients were disease-free. Mean time to LR was $33 \pm 21$ months (range: 10-51 months). Overall, LR occurred in 3 patients (4.1\%). One LR occurred after one additional procedure for RE (group 2) and the remaining two LR occurred in patients who underwent three surgical procedures (group 3). The patient with

Table 3 Binary logistic regression model. Odds ratio for the risk of re-excision.

\begin{tabular}{|c|c|c|}
\hline Factor & OR (95\% Cl) & p-value \\
\hline Type of surgery (OPS vs. BCT) & $0.84(0.30-2.32)$ & 0.74 \\
\hline Resection volume $(\mathrm{g})$ & & 0.39 \\
\hline$<50$ vs. $>50-\leq 150$ & $0.95(0.26-3.47)$ & 0.94 \\
\hline$<50$ vs. $>150$ & $2.04(0.59-7.05)$ & 0.26 \\
\hline Tumor stage (pT1 vs. pT2) & $0.51(0.13-2.02)$ & 0.34 \\
\hline Tumor size (1-20 vs. > $20 \mathrm{~mm}$ ) & $0.51(0.13-2.03)$ & 0.34 \\
\hline Nodal status (pN0 vs. pN1) & $0.78(0.26-2.35)$ & 0.66 \\
\hline Grading & & 0.68 \\
\hline G1 vs. G2 & $0.53(0.12-2.37)$ & 0.41 \\
\hline G1 vs. G3 & $0.76(0.18-3.20)$ & 0.71 \\
\hline Tumor-free margin status $(\mathrm{mm})^{\S}$ & & 0.008 \\
\hline $0-1$ vs. $2-3$ & $1.60(0.23-10.95)$ & 0.63 \\
\hline $0-1$ vs. $4-10$ & $2.00(0.29-13-91)$ & 0.48 \\
\hline $0-1$ vs. $>10$ & $10.40(1.93-55.10)$ & 0.006 \\
\hline EIC & & 0.60 \\
\hline Presence of EIC vs. no EIC & $1.63(0.58-4.53)$ & 0.35 \\
\hline No EIC vs. $<25 \%$ EIC & $1.37(0.35-5.35)$ & 0.65 \\
\hline No EIC vs. $>25 \%$ EIC & $1.86(0.55-6.27)$ & 0.32 \\
\hline $\begin{array}{l}\text { Hormone receptor status (positive } \\
\text { vs. negative) }\end{array}$ & $1.06(0.36-3.10)$ & 0.92 \\
\hline
\end{tabular}

Groups 1 and 2 were merged as no additional surgery was needed.

Increased tumor-free margins (in $\mathrm{mm}$ ) were achieved with increased

numbers of re-excisions.

OPS: oncoplastic surgery; BCT: breast-conserving therapy; ${ }^{\S}$ no difference whether BCT or OPS was performed $(\mathrm{p}=0.86)$
LR in group 2 had OPS, while the patients with LR in group 3 underwent BCT.

\section{Discussion}

Aim of this study was to identify risk factors for RE and LR in patients undergoing BCT and OPS. The presence of lymphovascular invasion or associated DCIS correlated positively with positive margins. Although our results do not show any new aspects, they reflect the inconsistent data and controversial discussion of risk factors for RE.

Other studies reported increased RE rates in younger patients and in patients with EIC or DCIS, which we could not confirm [3, $16,17,36]$. Other factors such as multifocality, tumor size ( $>3 \mathrm{vs}$. $<3 \mathrm{~cm}$; $>2$ vs. $\leq 2 \mathrm{~cm}$ and T3 tumor vs. T1-T2 tumors), micro-calcifications, presence of EIC, age $(\leq 45$ vs. $>45$ years and $<50$ vs. $\geq 50$ years), negative estrogen receptor status, lobular histological type, absence of preoperative diagnosis, or diagnosis by excision biopsy (vs. other) have been described as individual risk factors for RE $[3,18-24,37,38]$. Of these, only multifocal disease, lobular histological type, presence of micro-calcifications or EIC, age and tumor size have been independently reported in two or more publications as predictive for possible RE [25]. An observational study of 2206 women reported an overall RE rate of $22.9 \%$ with substantial variations between surgeons and institutions following partial mastectomy [26]. Meier-Meitinger et al. identified tumor size and accurate pre-surgical tumor staging as independent predictors for the need of a second surgical procedure or mastectomy [27]. The most consistent and reliable risk factors for RE appear to be the presence of micro-calcifications, EIC, and lobular histological type.

With the improvement of mammography techniques including the introduction of full-field digital mammography, micro-calcifications and their extent can now be identified better; this is important as higher mammographic density is also associated with a higher risk for a secondary surgical procedure following BCT [23].

Our data highlight the difficulties of assessing whether data are correlated with RE rates. In our view, risk factors for RE, with the exception of lobular histology, are not necessarily related to tumor biology but more to the limitations of imaging techniques $[28,29,35]$. The observation that younger patients have a higher risk of RE is not surprising, as breast density is higher in younger women (American College of Radiology [ACR] grade 3-4) [23]. Age is correlated with breast density and this in turn affects the likelihood of requiring RE. In our cohort, younger patients, in whom the interpretation of mammography data was potentially more difficult, tended to have OPS rather than BCT.

The impact of multiple REs on LR could not be investigated in our study due to the low numbers of events, but multiple REs do not seem to have an impact on LR rates if negative margins were obtained $[2,12,30]$. Coopey et al. reported an acceptably low risk of local and systemic failure when negative margins were achieved, irrespective of the number of previous REs [31].

New technologies which could detect tumor cells at, or close to, the margin of resection immediately after excision could increase the rates of complete excision at primary surgery, resolving the discussions about RE rates in the future [32]. First results using a radiofrequency-guided spectroscope to assess intraoperative margins are promising and could significantly reduce the RE rate $[33,34]$. Accurate preoperative tumor assessment and the use of 
elastography, MRI or automated whole breast ultrasound are additional technologies which could reduce RE rates [27].

Our study had some limitations. It was performed retrospectively. Although all patients who did not qualify for BCT and who had salvage mastectomy within 1-4 months after the first operation were excluded, the number of patients who chose mastectomy rather than RE is unknown and may have biased the results. The same applies to the limited number of patients. The reason for the high rate of REs in the whole cohort is unclear, as it does not represent the actual RE rate in our daily practice. It could be explained by the high number of patients who did not fulfill the inclusion criteria, which may have biased the overall $\mathrm{RE}$ rate. An additional limitation was the differences in systemic treatment, as some patients received chemotherapy and others did not. Nevertheless, all patients were treated in accordance with national guidelines, the aim of which is to guarantee adequate treatment with regard to LR and tumor stage.

\section{Conclusion}

\section{$\nabla$}

Our data did not reveal new risk factors for RE and reflect the inconsistent data and controversial discussions regarding risk factors for RE. However, we are of the opinion that breast cancers should be excised in a single surgical procedure and oncoplastic procedures should be considered. New technologies which could assess the preoperative tumor size and intraoperative margin status more accurately might reduce RE rates.

\section{Acknowledgement}

$\nabla$

The authors thank Julia Kremer for proofreading the English manuscript.

\section{Financial disclosure}

$\nabla$

All financial support was handled by the authors themselves, University Hospital Basel, Switzerland, and the Breast Cancer Center Rheinfelden, Germany. All authors declare no conflict of interest.

\section{Conflict of Interest \\ $\nabla$}

None.

\section{References}

1 Caughran JL, Vicini FA, Kestin LL et al. Optimal use of re-excision in patients diagnosed with early-stage breast cancer by excisional biopsy treated with breast-conserving therapy. Ann Surg Oncol 2009; 16: 3020-3027

2 Tartter PI, Kaplan J, Bleiweiss I et al. Lumpectomy margins, reexcision, and local recurrence of breast cancer. Am J Surg 2000; 179: 81-85

3 Aziz D, Rawlinson E, Narod SA et al. The role of reexcision for positive margins in optimizing local disease control after breast-conserving surgery for cancer. Breast J 2006; 12: 331-337

4 Yiu CC, Loo WT, Lam CK et al. Presence of extensive intraductal component in patients undergoing breast conservative surgery predicts presence of residual disease in subsequent completion mastectomy. Chin Med J (Engl) 2009; 122: 900-905
5 Holland R, Connolly JL, Gelman R et al. The presence of an extensive intraductal component following a limited excision correlates with prominent residual disease in the remainder of the breast. J Clin Oncol 1990; 8: 113-118

6 Sanchez C, Brem RF, McSwain AP et al. Factors associated with re-excision in patients with early-stage breast cancer treated with breast conservation therapy. Am Surg 2010; 76: 331-334

7 Mirza NQ Vlastos G, Meric F et al. Predictors of locoregional recurrence among patients with early-stage breast cancer treated with breastconserving therapy. Ann Surg Oncol 2002; 9: 256-265

8 Smitt MC, Nowels KW, Zdeblick MJ et al. The importance of the lumpectomy surgical margin status in long-term results of breast conservation. Cancer 1995; 76: 259-267

9 AGO: AGO Breast Commission. Diagnosis and treatment of patients with primary and metastatic breast cancer. Recommendations 2009. www. ago-online.de

10 Morrow M, Strom EA, Bassett LW et al. Standard for breast conservation therapy in the management of invasive breast carcinoma. CA Cancer J Clin 2002; 52: 277-300

11 Menes TS, Tartter PI, Bleiweiss I et al. The consequence of multiple reexcisions to obtain clear lumpectomy margins in breast cancer patients. Ann Surg Oncol 2005; 12: 881-885

12 O'Sullivan MJ, Li T, Freedman G et al. The effect of multiple reexcisions on the risk of local recurrence after breast conserving surgery. Ann Surg Oncol 2007; 14: 3133-3140

13 Meric F, Mirza NQ Vlastos G et al. Positive surgical margins and ipsilateral breast tumor recurrence predict disease-specific survival after breast-conserving therapy. Cancer 2003; 97: 926-933

14 Clough KB, Kaufman GJ, Nos C et al. Improving breast cancer surgery: a classification and quadrant per quadrant atlas for oncoplastic surgery. Ann Surg Oncol 2010; 17: 1375-1391

15 Singletary SE, Allred C, Ashley P et al. Revision of the American Joint Committee on Cancer staging system for breast cancer. J Clin Oncol 2002; 20: 3628-3636

16 Miller AR, Brandao G, Prihoda TJ et al. Positive margins following surgical resection of breast carcinoma: analysis of pathologic correlates. J Surg Oncol 2004; 86: 134-140

17 Wazer DE, Schmidt-Ullrich RK, Ruthazer R et al. The influence of age and extensive intraductal component histology upon breast lumpectomy margin assessment as a predictor of residual tumor. Int J Radiat Oncol Biol Phys 1999; 45: 885-891

18 Kurniawan ED, Wong MH, Windle I et al. Predictors of surgical margin status in breast-conserving surgery within a breast screening program. Ann Surg Oncol 2008; 15: 2542-2549

19 Smitt MC, Horst K. Association of clinical and pathologic variables with lumpectomy surgical margin status after preoperative diagnosis or excisional biopsy of invasive breast cancer. Ann Surg Oncol 2007; 14: 1040-1044

20 Cabioglu N, Hunt KK, Sahin AA et al. Role for intraoperative margin assessment in patients undergoing breast-conserving surgery. Ann Surg Oncol 2007; 14: 1458-1471

21 Dillon MF, Hill AD, Quinn CM et al. A pathologic assessment of adequate margin status in breast-conserving therapy. Ann Surg Oncol 2006; 13 : 333-339

22 Chagpar AB, Martin 2nd RC, Hagendoorn LJ et al. Lumpectomy margins are affected by tumor size and histologic subtype but not by biopsy technique. Am J Surg 2004; 188: 399-402

23 Bani MR, Lux MP, Heusinger $K$ et al. Factors correlating with reexcision after breast-conserving therapy. Eur J Surg Oncol 2009; 35: 32-37

24 Sakr RA, Poulet B, Kaufman GJ et al. Clear margins for invasive lobular carcinoma: A surgical challenge. Eur J Surg Oncol 2011; 37: 350-356

25 Pleijhuis RG, Graafland M, de Vries J et al. Obtaining adequate surgical margins in breast-conserving therapy for patients with early-stage breast cancer: current modalities and future directions. Ann Surg Oncol 2009; 16: 2717-2730

26 McCahill LE, Single RM, Aiello Bowles EJ et al. Variability in reexcision following breast conservation surgery. JAMA 2012; 307: 467-475

27 Meier-Meitinger M, Rauh C, Adamietz B et al. Accuracy of radiological tumour size assessment and the risk for re-excision in a cohort of primary breast cancer patients. Eur J Surg Oncol 2012; 38: 44-51

28 Rauh C, Hack C, Häberle L et al. Percent mammographic density and dense area as risk factors for breast cancer. Geburtsh Frauenheilk 2012; 72: 727-733

29 Kümmel S, Kolberg HC, Lüftner D et al. Breast cancer 2011 - new aspects. Geburtsh Frauenheilk 2011; 71: 939-953 
30 Swanson GP, Rynearson K, Symmonds R. Significance of margins of excision on breast cancer recurrence. Am J Clin Oncol 2002; 25: 438-441

31 Coopey S, Smith BL, Hanson $S$ et al. The safety of multiple re-excisions after lumpectomy for breast cancer. Ann Surg Oncol 2011; 18: 37973801

32 Allweis TM, Kaufman Z, Lelcuk S et al. A prospective, randomized, controlled, multicenter study of a real-time, intraoperative probe for positive margin detection in breast-conserving surgery. Am J Surg 2008; 196: 483-489

33 Thill M, Roder K, Diedrich $K$ et al. Intraoperative assessment of surgical margins during breast conserving surgery of ductal carcinoma in situ by use of radiofrequency spectroscopy. Breast 2011; 20: 579-580
34 Pappo I, Spector R, Schindel A et al. Diagnostic performance of a novel device for real-time margin assessment in lumpectomy specimens. J Surg Res 2009; 160: 277-281

35 Schulz-Wendtland R, Dilbat G, Bani MR et al. Use of tomosynthesis in intraoperative digital specimen radiography - is a reduction of breast re-excision rates possible? Geburtsh Frauenheilk 2011; 71: 1080-1084

36 Böhm J, Zikán M. Einfluss der prognostischen Faktoren auf die Therapie des duktalen Carcinoma in situ der Brust. Geburtsh Frauenheilk 2011; 71: 967-972

37 Fasching PA, Ekici AB, Adamietz BR et al. Breast cancer risk - genes, environment and clinics. Geburtsh Frauenheilk 2011; 71: 1056-1066

38 Hartkopf $A D$, Banys M, Krawczyk $N$ et al. Circulating tumor cells in early-stage breast cancer. Geburtsh Frauenheilk 2011; 71: 1067-1072 